УДК 664.126

\title{
ВЗАЄМОДІЯ ТВЕРДИХ І РІДКИХ ФАЗ, РУШІЙНІ СИЛИ РОЗТІКАННЯ, АДГЕЗІЯ, ЗМОЧУВАННЯ
}

Басок Б.І. ${ }^{1}$, член-кореспондент НАН України, Кулінченко В.Р. ${ }^{2}$, докт. техн. наук, Каптановський Д.В. ${ }^{3}$

${ }^{1}$ Інститут технічної теплофізики НАН України, вул. Желябова, 2а, м. Київ, 03680

${ }^{2}$ Національний університет харчових технологій, вул. Володимирська, 68, м. Київ, 01033

3 Черкаський державний технологічний університет, бульвар Шевченка, 460, 18006, м. Черкаси

Авторами проаналізовані основні рівняння молекулярної теоpiї капілярності і умови їх використання при незворотних процесах змочування. Встановлено, що рівняння Юнга, Дюпре, Лапласа i Кельвіна при незворотних процесах взаємодії рідких фаз, що конденсуються, та твердих фаз, не можна використовувати, бо вони виведені в умовах зворотного ізотермічного процесу і визначаються дією міжмолекулярних сил.
Авторами выполнен анализ основных уравнения молекулярной теории капиллярности и условия их использования при необратимых процессах смачивания. Установлено, что уравнение Юнга, Дюпре, Лапласа и Кельвина при необратимых процессах взаимного действия жидких фаз, которые конденсируются и твердых фаз, нельзя использовать, потому что они выведены в условиях обратимого процесса и подчинены действию молекулярных сил.
The authors analyzed the molecular theory basic equation of capillarity and conditions for their using in irreversible wetting processes. It was established that Young's equation, Dupre's equation, Laplace's equation and Kelvin's equation in mutual action irreversible processes of liquid phases, which are condensed and solid phases, can not be used because they (equations) are derived in a reversible process and subjected to the action of the molecular forces.

Бібл. 5.

Ключові слова: капілярність, змочування, фаза, незворотний процес, ізотермічний процес.

$F$ - сила розтікання, $\mathrm{H}$;

$W$ - робота, Дж;

$\theta-$ крайовий кут. град;

$\sigma-$ поверхневий натяг, Н/м;

\section{Індекси:}

А - адгезія;

K - когезія;

$\Gamma-$ газ;

р - рідина;

Для моделювання і управління технологічними процесами, пов'язаними 3 особливостями властивостей реологічних харчових органічних i неорганічних продуктів, а так само при з'єднанні матеріалів і синтезі композитів, необхідний аналіз фізико-хімічних закономірностей взаємодії твердих і рідких фаз. Зокрема, необхідне визначення рушійних сил змочування, капілярної течії і розтікання рідини по поверхні твердих і рідких фаз. [1] Поверхневі явища відіграють також визначальну роль в процесах екстракції і капілярного просочування твердих руш - рушійна сила;

т - тверде тіло;

$d$ - динамічне значення твердих і рідких фаз на межі з газом (або іншою рідиною, що не принципово);

$\sigma_{\text {тр }}-$ міжфазний натяг;

$\theta$ - крайовий кут змочування;

$W_{\mathrm{A}}$ і $W_{\mathrm{K}}-$ робота адгезії і когезії рідини.

тіл розчинами. Велике значення має аналіз поняття адгезії [3] і закономірності зміни динамічних значень поверхневих натягів на всіх трьох межах.

Проаналізовані основні рівняння молекулярної теорії капілярності і умови їх використання при незворотних процесах змочування [5]. Наведені визначення явищ: змочування, розтікання і адгезії з позицій сучасних представлень фізичної хімії.

Розглянуті умови використання рівнянь Юнга, Дюпре, Лапласа і Кельвіна при незворот- 
них процесах взаємодії твердих і рідких фаз, що конденсуються. Юнгом отримані рівняння [4]:

$\cos \theta=2 W_{\mathrm{A}} / W_{\mathrm{K}}-1 ;$

при $W_{\text {К }}=2 \sigma_{\text {рг }}$ маємо $W_{\mathrm{A}}=\sigma_{\text {рг }}(1+\cos \theta)$

i $\cos \theta=\left(\sigma_{\text {тг }}-\sigma_{\text {тр }}\right) / \sigma_{\text {рг }} ;$ або $\mathrm{K}=\cos \theta$,

де К - коефіцієнт змочування, що характеризує інтенсивність змочування за рівноважних умов; $\sigma_{\text {тг }}$ i $\sigma_{\text {рг }}-$ поверхневі натяги.

3 (1) і (2) також слідує вираз для визначення $F_{\text {руш }}-$ рушійної сили розтікання:

$F_{\text {руш }}=\sigma_{\text {тг }}-\sigma_{\text {тр }}=\sigma_{\text {рг }} \cos \theta$.

Відповідно до формалізму рівняння (2) коефіцієнт змочування $\mathrm{K}=\cos \theta$ можна використовувати тільки у випадку, якщо $-1 \leq \mathrm{K} \leq 1$ при $0^{\circ} \leq \theta \leq 180^{\circ}$.

Дюпре вивів рівняння для роботи зворотного відділення рідини від поверхні твердого тіла $W_{\text {А }}$ - роботи адгезії

$W_{\mathrm{A}}=\sigma_{\text {тг }}+\sigma_{\mathrm{pг}}-\sigma_{\text {тр }}=\sigma_{\mathrm{pr}}(1+\cos \theta)$.

Рівняння (4) визначає зміну вільної енергії системи при переході із стану контакту тверда фаза - рідина до стану тверда фаза - газ і рідка фаза - газ в результаті зворотного ізотермічного процесу розділення. Цей тип контакту називається зворотною адгезією, при якій поверхні можуть бути розділені на фази, залишаючись при цьому незмінними. Рівняння Юнга, Дюпре і Лапласа виведені в умовах зворотного ізотермічного процесу i визначаються дією міжмолекулярних сил, тобто коли $W_{\mathrm{K}}>W_{\mathrm{A}}$. При незворотних процесах (змочування, розтікання) $W_{\mathrm{A}}<W_{\text {К. }} 3$ аналізу рівняння (1) виходить, що $W_{\mathrm{A}}$ не може буті більше одиниці. На цю суперечність, в літературі, як нам відомо, практично не звертають увагу. Формули Юнга (1) і (2) отримані як проекція на ось $\mathrm{O} x$ загального сумарного вектора поверхневих натягів $\sigma_{i j}$ в рівноважних умовах і не відображають вертикальну складову цього вектора.
Наявність вертикальної складової твердого тіла (пружна і пластична деформація) викликає викривлення контактних поверхонь тонких підкладок. 3 розгляду векторів сил виходить, що три поверхневі натяги ні при якій формі краплі не можуть мати рівновагу, оскільки $\sigma_{\text {тг }}$ і $\sigma_{\text {тр }}$ лежать в одній площині і направлені одна проти іншої, а третя $\sigma_{\text {рг }}$ розташована під кутом.

Тому є сила, що не компенсується, прикладена до контуру краплі і спрямована вертикально вгору [2]. Опукла поверхня краплі створює капілярний тиск Лапласа, який притискує іï до плоскої поверхні. Для того, щоб капілярний тиск був урівноважений по всій поверхні, що обмежує краплю, необхідне формування лунки під нею так, щоб всі три сили уздовж контуру компенсувалися.

\section{Висновки:}

1. Рівняння Юнга не враховує вертикальну складову вектора $\sigma_{\text {рг }}$ i коректність його використання для нерівноважних систем і вимагає спеціального аналізу. В умовах рівноваги це рівняння не може бути використане при незворотних процесах змочування i розтікання, оскільки $\cos \theta$ не може бути більше одиниці.

2. Для систем, далеких від рівноваги $(\Delta \mu \neq 0)$, використання рівнянь Юнга $\mathrm{i}$ Дюпре коректне i $W_{\mathrm{K}}$ збільшується і може застосовуватися тільки для аналізу динамічних значень $\sigma_{\text {рг }}{ }^{d}, W_{\mathrm{A}}{ }^{d} \mathrm{i}$ $Q^{d}$, на стадії швидкого розтікання.

3. Фізичний сенс поняття, у разі нерівноважного розтікання, відрізняється від поняття роботи адгезії, використовуваної в рамках молекулярної теорії капілярності. У нерівноважних системах характеризує енергію міжатомної взаємодії двох фаз, що конденсуються, в області межі між фазами.

\section{ЛІТЕРАТУРА}

1. Воюикий С.С. Аутогезия и адгезия высокополимеров. Ростов: Ростовиздат, 1960. - 244 с.

2. Гупало А.П., Ватаманюк Н.М. Высокомолекулярные соединения. М.: Издательство НМКВО, 1993. - 243 c.

3. Кулінченко В.Р. Гідравліка, гідравлічні машини і гідропривід: Підручник. К.: Фірма IНКОС, 2006. $-616 \mathrm{c}$. 
4. Остроумов С.А., Лазарева Е.В. Поверхностное натяжение водных растворов додецисульфита в присутствии водных растений. Вода: технология и экология, 2008, № 3. - С 57-60.

\section{INTERACTION OF SOLID AND LIQUID PHASES. DRIVING FORCES SPREADING, ADHESION, MOISTENING}

\author{
Basok B.I. ${ }^{1}$, Kulinchenko V.R. ${ }^{2}$, Kaptanovskiy D.V. ${ }^{3}$ \\ ${ }^{1}$ Institute of Engineering Thermophysics \\ of the National Academy of Sciences of Ukraine, \\ vul. Zhelyabova, 2a, Kyiv, 03680, Ukraine \\ ${ }^{2}$ National University of Food Technology, \\ vul. Vladymyrskaya, 68, Kyiv, 01033, Ukraine \\ ${ }^{3}$ Cherkasskiy State Technological University, \\ Shevchenko, 460, Cherkassy, Ukraine
}

The authors analyzed the molecular theory basic equation of capillarity and conditions for their using in irreversible wetting processes. It was established that Young's equation, Dupre's equation, Laplace's equation and Kelvin's equation in mutual action irreversible processes of liquid phases, which are condensed and solid phases, can not be used because they (equations) are derived in a reversible process and subjected to the action of the molecular forces. Ref. 5.
5. Фролов Ю.Г. Курс коллоидной химии. Поверхностные явления и дисперсные системы: Учебник. М.: 1988. - 340 с.

Key words: capillarity, moistening, phase, irreversible process, isothermal process.

1. Voyuckij S.S. Autogeziya i adgeziya vysokopolimerov. Rostov: Rostovizdat, 1960. - 244 s. (Rus)

2. Gupalo A.P., Vatamanyuk N.M. Vysokomolekulyarnye soedineniya. M.: Izdatelstvo NMKVO, 1993. - 243 s. (Rus)

3. Kulinchenko V.R. Gidravlika, gidravlichni mashini i gidroprivid: Pidruchnik. K.: Firma INKOS, 2006. - 616 s. (Ukr)

4. Ostroumov S.A., Lazareva E.V. Poverxnostnoe natyazhenie vodnyx rastvorov dodecisulfita $\mathrm{V}$ prisutstvii vodnyx rastenij. Voda: Texnologiya i ekologiya, 2008, № 3. - s. 57-60. (Rus)

5. Frolov Yu.G. Kurs kolloidnoj ximii. Poverxnostnye yavleniya i dispersnye sistemy: Uchebnik. M.: 1988. - 340 s. (Rus)

Отримано 21.10.2014 Received 21.10.2014 